\title{
A leitura e sua contribuição no processo da aprendizagem na alfabetização
}

\author{
Reading and its contribution to the learning process in literacy \\ La lectura y su contribución al proceso de aprendizaje en la alfabetización \\ Lesen und sein Beitrag zum Lernprozess in der Alphabetisierung \\ La lecture et sa contribution au processus d'apprentissage en alphabétisation \\ La lettura e il suo contributo al processo di apprendimento nell'alfabetizzazione \\ Чтение и его вклад в процесс обучения грамоте \\ 読書とリテラシーにおける学習過程への貢献 \\ 阅读及其对识字学习过程的促进作用
}

Maria José Tavares de Lima
Escola Municipal Sandoval Ribeiro Dantas (Nísia Floresta, RN/, Brasil)
mariatlima2@gmail.com
Marcelo Firmino da Silva
Escola Municipal José Alexandre de Lima (Santo Antônio, RN, Brasil)
marcelof1981@yahoo.com.br

Páginas 119-128

Fecha recepción:25/09/2020

Fecha aceptación:29/12/2020

\section{Resumo.}

Este artigo tem como temática a leitura e sua contribuição no processo da aprendizagem na alfabetização. 0 objetivo é de incentivar e estimular o prazer e 0 interesse pelo mundo da leitura, e contribuir de forma eficaz para alfabetização, enriquecendo as aulas dos professores através de dinâmicas e possibilitando uma troca de teoria e prática das relações sociais em sala de aula. A metodologia aplicada foi à revisão bibliográfica da temática em estudo através do Google Acadêmico, onde foi selecionado trabalhos de vários pesquisadores na área. Conclui-se que a proposta da leitura no Ensino Fundamental é formar leitores críticos e participativos, que saibam agir sempre utilizando a ética e o moral, que é através dos conhecimentos adquiridos todos possam crescer com uma visão de mundo. A leitura é como aspecto fundamental para o desenvolvimento da nossa vida escolar e tem um espaço fundamental na alfabetização para além do ensino sistematizado.

Palavras chave: leitura; aprendizagem; alfabetização; contribuição; processo

\section{Abstract.}

This article is about reading and its contribution to the learning process in literacy. The objective is to encourage and stimulate pleasure and interest in the world of reading, and contribute effectively to literacy, enriching teachers' classes through dynamics and enabling an exchange of theory and practice of social relations in the classroom. The methodology applied was the bibliographic review of the subject under study through Google Academic, where works of several researchers in the area were selected. It is concluded that the proposal of reading in elementary school is to form critical and 
participatory readers, who know how to act always using ethics and morals, which is through the knowledge acquired everyone can grow with a world view. Reading is a fundamental aspect for the development of our school life and has a fundamental space in literacy beyond systematic education.

Keywords: reading; learning; literacy; contribution; process

\section{1.-Introdução.}

Este artigo tem como temática: "A Leitura e sua Contribuição no Processo da Aprendizagem na Alfabetização". O presente trabalho foi desenvolvido na turma do $4^{\circ}$ Ano do Ensino Fundamental, numa escola do município de Várzea, RN. O objetivo é de incentiva e estimular o prazer e o interesse pelo mundo da leitura, e contribuir de forma eficaz para alfabetização, enriquecendo as aulas dos professores através de dinâmicas e possibilitando uma troca de teoria e prática das relações sociais em sala de aula. A proposta da leitura no Ensino Fundamental é formar leitores críticos e participativos, que saibam agir sempre utilizando a ética e o moral, que é através dos conhecimentos adquiridos todos possam crescer com uma visão de mundo. A leitura é como aspecto fundamental para o desenvolvimento da nossa vida escolar e tem um espaço fundamental na alfabetização para além do ensino sistematizado.

A importância de despertar o interesse pela leitura, pelos os livros entre os alunos e 0 estimulo aos pais para que eles possam ler para os seus filhos em casa. Devemos ler para se informar, através da leitura realizada com prazer, é possível desenvolver a imaginação da criança e enriquecendo o vocabulário, envolvendo linguagens diferenciadas, por isso a alfabetização e a prática da leitura de textos literário, contos, fabulas e lendas dentro ou fora de aula precisa ser estimulado pelo os docentes e também pela as famílias, porque a leitura é muito importante no desenvolvimento do ensino fundamental. É preciso que o professor esteja sempre lendo para os nossos alunos e estimulando-os a ler, pois, a leitura é um componente da educação sendo um processo, e devemos sempre buscar conhecimento, pois é lendo que adquirimos novos conhecimentos através da leitura que aprendemos a ler e a escrever. Porque quem possui o hábito de ler, torna-se mais analítico e contextual, sendo cada vez mais aumentando sua capacidade criativa e seu raciocínio lógico.

O professor tem um grande papel na formação de leitores, a importância do habito de leitura precisa a todo tempo ser evidenciada pelo educador em sala de aula, fazendo assim, com que seu aluno desperte para o quão necessário se tornar a leitura em seu dia a dia. É necessário que haja um estimulo continuo para o contato entre o indivíduo e o livro: (...) o professor deve proporcionar várias atividades inovadas, procurando conhecer os gostos de seus alunos e a partir daí escolher um livro ou uma história que vá ao encontro das necessidades da criança, adaptando o seu vocabulário, despertando esse educando para o gosto, deixando-o se expressar (Souza, 2004, p.223). 
Percebemos a importância de colaborar que o aluno leia com domínio os diferentes gêneros e compreenda a leitura em seus diversos objetivos, proponho um trabalho de incentivo à leitura, a fim de que os nossos alunos conheçam os diferentes objetivos de leitura, tenham um maior acesso à diferentes portadores de textos, especialmente, os textos literários.

Mesmo antes de começar a frequentar a escola, a criança já possui uma série de conhecimento sobre a língua escrita. Esses conhecimentos são decorrentes da interação sociocultural que ela mante ou manteve com a escrita e da relação com pessoas já alfabetizadas, relação esta que ocorre nos mais diversos contextos sociais em que ler e escrever tem função social. Mesmo as crianças sendo filhos de pais nãoalfabetizados ou com baixo nível de escolarização, ou ainda aquela que vive em zonas não-urbanas, pode possuir algum conhecimento sobre a função da escrita. Tendo isso por pressuposto, ao receber 0 aluno para $01^{\circ}$ e $2^{\circ}$ anos do ensino fundamental, 0 professor deve partir dos conhecimentos prévios dos alunos para leva-los a construir novos conhecimentos acerca da língua escrita.

Nesse nível de escolarização, o aluno precisa entender a escrita como um objeto social e não como um objeto escolar. Isso será possível a partir de uma prática pedagógica em que a leitura e a escrita sejam trabalhadas de maneiras significativa. Ler é mais complexo do que saber decodificar (isto é, transformar sinais gráficos em sons) e escrever vai mais além de saber codificar (ou seja, transformar sons em sinais gráficos). Saber ler implica em compreender as intencionalidades do texto, as características próprias dos gêneros, os efeitos provocados pelas escolhas linguísticas do autor etc. Saber escrever consiste em produzir um discurso, coerente e coeso conforme uma intenção comunicativa.

Diante disso, ensinar o nome das letras e o valor sonoro delas é uma tarefa importante e necessária para o professor alfabetizador, mas não deve ser a única. Pode-se dizer que, nos primeiros anos de escolarização, o professor precisa garantir ao aluno a alfabetização, ou seja, a habilidade de ler (decodificar) e escrever (codificar), mas também o letramento. A respeito desses conceitos esclarecem Leal, Albuquerque e Morais (2006, p. 71)

O primeiro termo, alfabetização, corresponderia ao processo pelo qual se adquire uma tecnologia a escrita alfabética e as habilidades de utilizá-la para ler e escrever. Dominar tal tecnologia envolver conhecimentos e destrezas variados, como compreender o funcionamento do alfabeto, memorizar as convenções letras-som e dominar seu traçado, usando instrumentos como lápis, papel ou outros que os substituam. Já o segundo termo, letramento, relaciona-se ao exercício efetivo e competente daquela tecnologia da escrita, nas situações em que precisamos ler e produzir textos reais.

Alfabetização e Letramento, conforme explica Soares (2003), não são práticas excludentes, pelo contrário. Ao mesmo tempo em que ensina a natureza do sistema de escrita, o professor pode e deve propor atividades de leitura e escrita de textos. 
Desse modo, alfabetização letrada ou, alterando a ordem dos termos, mas não os princípios, letrará alfabetizando. Conforme já dissemos, muitas crianças chegam à escola com os conhecimentos absorvidos informalmente em seu cotidiano. Por isso, a leitura como grande instrumento facilitador da aprendizagem precisa ganhar lugar de destaque nas escolas. É preciso uma maior conscientização por parte dos educadores, em buscar formas de incentivar o seu aluno a ter o prazer pela a leitura. Portanto, a prática da leitura se faz presente em nossas vidas desde do primeiro momento em que nós começamos a compreender o mundo a nossa volta, entretanto, a leitura é um instrumento essencial em nossa sociedade é muito importante ressaltar que a leitura é a base principal no processo de ensino e aprendizagem na formação dos alunos na alfabetização.

\section{2.-A importância de alfabetizar no ensino fundamental.}

Segundo Magda Soares, alfabetização é tornar o indivíduo capaz de ler e escrever, e o processo pelo qual a pessoa adquire o domínio de um código e das habilidades de utilizá-lo par ler e escrever, ou seja, domínio de técnicas pra exerce a arte e a ciência da escrita, e também o desenvolvimento de novas formas de compreensão e interpretação e uso da linguagem de uma maneira geral.

O surgimento do termo literacy (cujo o significado é o mesmo de alfabetização, nessa época, representou, certamente, uma mudança história nas práticas sociais, novas demandas sociais pelo uso da leitura e da escrita exigiram uma nova palavra para designá-las. Ou seja, uma nova realidade social trouxe a necessidade de uma nova palavra (Soares, 2011, p. 29).

Na verdade, estar alfabetizado é poder ir além do código escrito, é apropriar-se da função social constituinte dos atos de ler e escrever é fazer uso da leitura e da escrita no cotidiano, ser capaz de ler um livro, uma revista, um jornal, estar apto a escrever com total compreensão, ou seja, saber o que está lendo e escrevendo sem somente juntar as silabas, e poder no mundo da cultura conseguir acessar informações e delas se utilizar com senso crítico. O conceito de alfabetização para Freire (1975) diz que alfabetização tem um significado mais abrangente na medida em que vai além do domínio do código escrito, ele tinha uma visão mais ampla desse conceito, enquanto prática discursiva que possibilita uma leitura crítica da realidade. Ele defendia a ideia de que o ser humano aprende a ler o mundo bem antes de aprender a ler e escrever defendia que a leitura do mundo precede a leitura da palavra fundamentando se na antropologia: O ser humano, muito antes de inventar códigos linguísticos, já a lia o seu mundo. Vejamos alguns conceitos de alfabetização citados por alguns autores:

Enfim, ser alfabetizado não é só ser capaz de juntar letras para formar silabas, juntar silabas para forma palavras e palavras para formar frases e frases para forma textos, e sim saber o que está lendo e escrevendo ter noção de concordância saber se o que está escrevendo tem coerência dizer que um sujeito é alfabetizado não é tão simples como parece. 
"Progredir alfabetização adentro não é uma jornada tranquila. Encontram-se muitos altos e baixos nesse caminho, cujos significados precisam ser compreendidos. Como qualquer outro conhecimento no domínio cognitivo, é uma aventura excitante, repleta de incertezas, com muitos momentos críticos, no quais é difícil manter ansiedade sob controle" (Ferreiro, 2001).

Através de leituras sobre o tema foi possivel constatar que um conceito básico para a alfabetização é de que ela é um processo que leva a aprendizagem inicial da leitura e escrita. Ou seja, alfabetização é aquela pessoa que domina habilidades básicas para fazer uso da leitura. Para Val (2006, p.19), pode-se define alfabetização como 0 processo especifico e indispensável de apropriação do sistema de escrita, a conquista dos princípios alfabético e ortográfico que possibilitem ao aluno ler e escrever com autonomia, noutras palavras, alfabetização diz respeito à compreensão e ao domínio do chamado "código" escrito, se organizar em torno de relações entre a pauta sonora da fala e as letras (e ouras conversões) usadas para representa-la, na escrita.

A alfabetização é um processo que não termina, pois no decorrer de nossas vidas estamos sempre em constante aprendizagem, seja na questão intelectual na escrita ou na fala estar aprendendo é estar se alfabetizando.

Tem-se tentado, ultimamente, atribuir um significado demasiado abrangente a alfabetização, considerando-a um processo permanente, que se estenderia por toda vida, que não se esgotaria na aprendizagem da leitura e da escrita. É verdade que, de certa forma, a aprendizagem da língua materna, quer escrita, quer oral é um processo permanente, nunca interrompido. (Soares, 2012, pg.15).

Alfabetizar não é apena ensinar código de língua escrita não deve de maneira alguma ser um processo mecânico hoje não basta apenas saber ler e escrever, mas que se saiba fazer uso da leitura e da escrita.

Pode se concluir da discussão processo de alfabetização a respeito do conceito de alfabetização, que essa não é uma habilidade, é um conjunto de habilidades, o que a caracteriza como um fenômeno de natureza complexa, multifacetado. Essa complexidade e multiplicidade de facetas explicam porque o processo de alfabetização tem sido estudado por diferentes profissionais, que privilegiam ora estas ora aquelas habilidades, segundo a área do conhecimento a que pertencem (Soares, 2012, p.18).

A partir dos conceitos apresentados por alguns autores é importante constatar que a alfabetização ela é um processo de ensino aprendizagem que acontece antes, durante e depois do período escolar, porém, a alfabetização acontece dentro e fora do ambiente escolar. Portanto, as crianças que é incentivada a participar do universo da leitura ela terá mais oportunidade de desenvolver suas competências e habilidades, tornando-se um ser ativo na construção de uma sociedade mais letrada. Emília Ferreiro, nos seus trabalhos e pesquisas sobre crianças e seu processo de construção da escrita, alerta sempre para essa questão da interação entre o leitor em formação e 
o mundo da escrita. A criança que não convive em um ambiente alfabetizador, encontrará dificuldades de se integrar no cotidiano social.

O Referencial Curricular para a Educação Infantil (SEF,1998, p.151) diz que: (...) um ambiente é alfabetizador quando promove um conjunto de situações de usos reais de leitura e escrita nas quais as crianças tem a oportunidade de participar. Isso não significa que se deve fazer da sala um local cheio de matérias escrito, sem nenhum critério ou qualidade, mas sim transformá-la em um espaço no qual a leitura e a escrita estejam sempre presentes. Isso permite à criança perceber a importância dos textos e o prazer que a elaboração e a leitura deles podem proporcionar. Criar um ambiente alfabetizador também implica em respeitar as crianças enquanto pessoas. Elas precisam se sentir acolhidas, valorizadas e devem ter oportunidade de realizar aquilo que melhor sabem fazer nessa fase da vida: brincar e imaginar.

Além disso, um ambiente ideal para a alfabetização (ou, como preferem alguns, para o letramento) implica em instaurar um clima em que ocorra a interação entre professoraluno, aluno-aluno, aluno-família, professor-família, etc.

As sugestões a seguir podem ajudar o professor a estabelecer na sala de aula um ambiente alfabetizador:

-Afixar o alfabeto num mural ou varal da sala logo no início do ano. Ele servirá de referência para a realização de várias atividades;

- Colocar na parede, com ordem e clareza, cartazes significativos;

-Ter disponível um espaço (uma parede ou um mural ou painel) para que sejam afixadas as produções dos alunos, à medida que forem desenvolvidas;

-Planejar as aulas de modo que a leitura/escrita de textos faça parte da rotina da sala de aula;

-Ter um espaço físico Cantinho da Leitura ou Biblioteca da Classe) que proporcione aos alunos o contato com diversos portadores e gêneros textuais, como revistas, jornais, livros infantis, gibis etc.;

-Apresentar ao aluno, em qualquer fase do processo de aprendizagem, todo e qualquer material escrito, pois cada aluno vai recepcionar o texto e interagir com ele conforme seu nível de alfabetização/letramento;

-Promover atividades lúdicas, por meios das quais as crianças possam cantar, dançar, brincar, jogar etc.;

-Propiciar situações em que os educandos possam expor ideias, experiencias pessoais e pontos de vista. Enfim, o ambiente alfabetizador tem de possibilitar 0 desenvolvimento cognitivo do aluno para que ele possa avançar na aprendizagem, que consiste em um processo gradativo e continuo.

\section{3.-A importância do papel do educador na alfabetização.}

É com base nessas perspectivas, que o professor tem a função de mediador desse conhecimento, através de práticas de leitura e a escrita, de maneira que aconteça a aprendizagem efetiva na vida dos alunos. 0 professor possui um papel fundamental no processo de alfabetização: 0 de mediador da relação entre 0 aluno e a 
aprendizagem. Ele deve estar ciente de que, além de propor as atividades que planejou, deve ajudar a criança a avançar cognitivamente. Isso quer dizer que, em vez de deixar o aluno descobrir sozinho para que serve a escrita e de que modo ela representa graficamente 0 pensamento e a linguagem (prática que poderíamos chamar de espontaneísta), o professor auxilia a criança a refletir sobre suas preconcepções de modo que ela supere conceitos equivocados ou incompletos e substitua-os por novos conceitos. Segundo Massini-Cagliari e Cagliari (1999, p.225),

Ser "mediador" não pode ser entendido apenas como sendo um aplicador de pacotes educacionais ou mero constatador do que o aluno faz ou deixar de fazer. Ser mediador deve significar, antes de mais nada, estar entre 0 conhecimento e 0 aprendiz e estabelecer um canal de comunicação entre esses dois pontos.

Além de desempenhar o papel de mediador, o professor também tem o papel de educador. Ser educador significa orientar os alunos em todos os momentos, nas situações que possam surgir dentro e fora da escola. A orientação dada pelo professor tende a influenciar o desenvolvimento da criança; por isso, é fundamental que 0 professor aja com discernimento, boa vontade e respeito pelo que faz, pela escola e principalmente pelos os alunos, que são indivíduos que estão conhecendo o mundo e assimilando novos conceitos. Segundo Freire (1975, p. 67) "...Aprender a ler, a escrever, alfabetizar-se é, antes de mais nada, aprender a ler o mundo, compreender o seu contexto, não numa manipulação mecânica de palavras, mas numa relação dinâmica que vincula linguagem e realidade."

Ao se falar em alfabetização, o que deve vir a mente são os três eixos norteadores da mesma: s oralidade, a escrita e a leitura. Uma está ligada a outra incondicionalmente. Alfabetizar é levar a criança a ter prazer, gostar de falar, escrever e ler. Então, alfabetizar não é simplesmente decodificar códigos, símbolos, mas sim decodificar e interpretar o significado, fazer uma análise crítica de algo. Cada criança chegar á escola em uma fase da alfabetização o nível de compreensão depende das possibilidades prévias de contato com o mundo da escrita. Apesar de uma classe ter alunos em estágios diferentes de conhecimento, todos podem aprender. $\mathrm{O}$ ambiente escolar deve ser pensado para propiciar inúmeras interações com a língua escrita. 0 papel do professor é mediar interações.

Portanto, sendo assim, passa a ser o papel do professor:

,Tornar os conceitos e conteúdos possíveis de serem aprendidos pelos alunos, fornecendo as informações necessárias que eles não têm condições de obter sozinhos. Para isso, o professor deverá ter um amplo de conhecimento dos conteúdos a serem trabalhados;

-Conduzir e organizar o trabalho em sala de aula, buscando desenvolver a autonomia dos alunos;

-Estimular continuamente os alunos motivando-os a refletir, investigar, levantar questões e trocar ideias com os colegas. 
É importante que o professor conheça as condições socioculturais, as expectativas e as competências cognitiva dos nossos alunos, pois, dessa forma, ele terá condições de selecionar situações-problema relacionadas ao cotidiano dele. É relevante também o trabalho de um conteúdo em diversos contextos, a fim de induzir a capacidade de generalização nos alunos.

Cabe ao professor mostrar aos alunos várias atividades que sejam lúdicas, e ele possam trabalhar com diferentes textos literário. Como diz Freire $(2975$, p. 78$)$ "Ensinar não é transferir conhecimentos, mas criar as possibilidades para sua produção ou a sua construção. "Portanto, é importante que o professor em seu plano de aula envolva atividades lúdicas de leitura e escrita, bem como um ambiente alfabetizador deve ser convidativo, portanto, a sala de aula onde as crianças passam grande parte do dia, tem que ser motivadora, espaço de muitas leituras. A alfabetização é a base para uma educação construtiva, o qual ajuda as pessoas a desenvolver a leitura, a escrita, a comunicação, as ideias e os pensamentos.

\section{4.-Algumas sugestões de atividades de leitura rodam de leitura.}

O professor deve fazer todos os dias uma roda de conversas, através de uma leitura de textos literários, jornalísticos, contos de fada, historinhas e etc. Os gêneros devem ser variados para que o repertório se amplie com mais eficaz. Notícias que tratem de algum assunto relevante e interesse dos alunos. Através desta roda de leitura as crianças aprendem, os usos e as funções da escrita, as características que vai distinguem os gêneros e as diferenças entre o oral e o escrito.

Jogos de formação de palavras para a turma:

Escrever, algumas palavras em pedaço de cartolina, palavras que pertençam a diversas categorias (exemplos, brinquedos, plantas, animais e etc.)

Jogo de formar frase:

Produzir várias frases em cartolina com cores diferentes, contendo: alguns substantivos, ações, conectivos e pontuação, separadamente e etc.

Fazer atividades que chame a atenção dos alunos com o alfabeto.

Com essa atividade os alunos podem identificar as letras do alfabeto relacionando-as com os fonemas inicial de cada palavra e desenvolver a coordenação ampla dos alunos.

Ditado de palavras em baralho.

Deve preparar as cartas com algumas imagens na frente e a escrita das palavras relacionada no verso da cartolina.

Leitura em grupo, em sala de aula.

Através de um livro paradidático semanalmente, leitura dramatizada de capítulos de um livro ou um texto. 
Produção de textos.

Produzir cartas para os colegas da turma incentivando a leitura.

Produção de murais em sala de aula.

Para fazer a divulgação das cartinhas lidas pelos os aluno de sala de aula.

Trabalhar com diferentes gêneros:

Poemas, contos, lendas, etc.

Leituras de gêneros como:

Contos, poemas, crônicas, romances, jornais, revistas, historinhas em quadrinhos e etc.

Leitura oral e silenciosa em sala de aula.

Através desta leitura os alunos vão adquirir algumas habilidade e competências

Visita à biblioteca pública.

Através da visita a Biblioteca fazer pesquisa bibliográficas de autores conhecido da Literatura Brasileira. E também fazer o empréstimo de livros para ler em sala e em casa.

Exibições de filmes de acordo com o tema da aula.

Trazer vários filmes para as crianças assistir na sala de aula, que esteja no contexto do assunto da aula.

\section{5.-Considerações finais.}

Consideramos que a leitura e sua contribuição no processo da aprendizagem na alfabetização são de suma importância para os alunos. Diante do exposto pode-se perceber que a alfabetização possui vasta função social na medida em que é um processo de ensino aprendizagem inicial da leitura e escrita. Sendo assim, as pessoas alfabetizadas são aquelas que aprendem as habilidades básicas para fazer 0 uso da leitura e da escrita. Isso apesar da educação passar por várias transformações ao logo do tempo, ainda é muito predominante a utilização de métodos e práticas de alfabetização que tenha 0 aluno como um sujeito passivo, e apenas um receptor de informações, sendo assim um ato mecânico.

Entretanto, buscamos socializar as teorias de Ferreiro (2003), sobre as fases de desenvolvimento da escrita, Magda Soares para melhor entender sobre o processo de alfabetização, em Freire, que nos ensina que deve alfabetizar construindo 0 conhecimento, inserido o educando no seu meio social e Ana Teberosky que fala do processo de leitura e escrita e entre outros autores. Enquanto, a criança que lê com mais desenvoltura ela se interessa pela a leitura e aprender muito mais e pode se transforma num grande leitor. Sendo assim, não existe uma receita já pronta para alfabetização, cabe aos professores desempenhar um trabalho na sala de aula, com muita dedicação para fazer o melhor e pode alfabetizar a sua turma, e através deste 
trabalho ensinar as crianças a ler e ter o prazer pela a leitura. Portanto, assim, uma prática significativa depender do interesse do professor em planejar as suas aulas com coerência, visando a construção de conhecimentos com os alunos em sala de aula.

\section{6.-Referências.}

Albuquerque, E.B.C. Ferreira, A.T.B.F., \& Morais, A.G. (2006). As práticas cotidianas de alfabetização: o que fazem as professoras? Anais da $28^{a}$. Reunião Anual da ANPED. Disponível em www.anped.org.br/28/textos/gt101128int.rtf,maio de 2006.

Ferreiro, E. (2001). Reflexões Sobre a Alfabetização.24. São Paulo: Cortez.

Ferreiro, E. (2003). Escrita e oralidade: unidades, níveis e consciência metalinguística. In Ferreiro, E. (2003) (org.). Relações de (in) dependência entre oralidade e escrita. Porto Alegre: Artmed,2003.

Freire, P. (1975). Educação como prática da liberdade. Rio de janeiro: Paz e terra.

Freire, P. (1983). DA leitura da palavra à leitura do mundo. Leitura teoria e prática. Campinas: Cortez.

Freire, P. (1982). A Importância do Ato de Ler. São Paulo: Cortez.

MEC/SEF (1997). Parâmetros Curriculares Nacional: Terceiro e quarto ciclos do Ensino Fundamental: Introdução. Secretaria de Educação Fundamental. Brasília, DF: MEC/ SEF.

MEC/SEF (1997a). Parâmetros Curriculares Nacionais: Língua Portuguesa. Brasília: MEC/SEF.

MEC/SEF (1998). Referencial Curricular Nacional para a Educação Infantil. Brasília: MEC/SEF.

Soares, M. (2011). Letramento: um tema em três gêneros. Belo Horizonte: Autêntica.

Soares, M. (2011). Alfabetização e letramento. São Paulo: Contexto.

Val, M.G.C.O. (2006). Que é ser alfabetização e letrado? 2004. In: Carvalho, M.A.F. (org.) (2006). Práticas de Leitura e escrita. Brasília: Ministério da Educação. 